University of Nebraska - Lincoln

DigitalCommons@University of Nebraska - Lincoln

3-12-2001

\title{
A multiplex PCR assay for differentiating economically important gastrointestinal nematodes of cattle
}

Dante S. Zarlenga

M. Barry Chute

Louis C. Gasbarre

Patricia C. Boyd

Follow this and additional works at: https://digitalcommons.unl.edu/usdaarsfacpub

This Article is brought to you for free and open access by the U.S. Department of Agriculture: Agricultural Research Service, Lincoln, Nebraska at DigitalCommons@University of Nebraska - Lincoln. It has been accepted for inclusion in Publications from USDA-ARS / UNL Faculty by an authorized administrator of DigitalCommons@University of Nebraska - Lincoln. 


\title{
A multiplex PCR assay for differentiating economically important gastrointestinal nematodes of cattle
}

\author{
Dante S. Zarlenga*, M. Barry Chute, \\ Louis C. Gasbarre, Patricia C. Boyd
}

US Department of Agriculture, ARS, Immunology and Disease Resistance Laboratory, Bldg. 1180, BARC-East, Beltsville, MD 20705, USA

Received 17 November 2000; received in revised form 15 February 2001; accepted 12 March 2001

\begin{abstract}
A multiplex polymerase chain reaction (PCR) test was developed for identifying gastrointestinal (GI) nematodes that commonly infect cattle. This assay was developed using adult-derived genomic DNA and shown capable of discriminating parasite eggs from the feces of experimentally-infected animals at both the species and genus levels. Sequence data from internal (ITS) and external (ETS) transcribed spacers of the ribosomal DNA (rDNA) repeats as well as the $3^{\prime}$-end of the small subunit rDNA and 5'-end of the large subunit rDNA were used to generate five primer sets which, when used simultaneously in a multiplex PCR, produce a unique electrophoretic DNA banding pattern characterized by a single DNA fragment for Ostertagia ostertagi (257 bp), Haemonchus placei (176 bp), Oesophagostomum radiatum (329 bp), Trichostrongylus colubriformis (243 bp) and Cooperia oncophora (151 bp). In a similar manner, the constructed primer sets amplified DNA from Ostertagia lyrata, Haemonchus contortus, Trichostrongylus axei, Cooperia surnabada and Cooperia punctata. With respect to $H$. contortus, a closely migrating doublet was generated suggesting size heterogeneity in the ETS which is consistent with multiple rDNA repeat units within this species. PCR analyses using mixtures of monospecifically-purified nematode eggs indicated a sensitivity of less than 0.5 egg-DNA equivalent per species. Although, not designed as a quantitative technique, relative PCR signal intensities corresponded to relative egg burdens within the DNA samples from mixed species of eggs. Published by Elsevier Science B.V.
\end{abstract}

Keywords: Diagnosis; Polymerase chain reaction; Multiplex; Gastrointestinal nematode; Ribosomal DNA

\footnotetext{
* Corresponding author. Tel.: +1-301-504-8754; fax: +1-301-504-8979.

E-mail address: zarlenga@anri.barc.usda.gov (D.S. Zarlenga).
} 


\section{Introduction}

Gastrointestinal (GI) nematode infections of ruminants remain a major constraint to the efficient raising of livestock throughout the world. In the US it is estimated that these parasites cost the American cattle industry in excess of US\$ 2 billion per year in lost productivity, and higher operating expenses. Given the ubiquitous nature of GI nematodes, the variability in host susceptibility to parasites, the presence of wild ruminants which can serve as sources of infection, and the relationship between optimal conditions for parasite transmission and optimal conditions for grass growth, it has been an arduous task to eradicate GI nematodes in grazing ruminants. Thus, the goal of effective nematode control is to protect cattle from production losses by reducing parasite transmission and the rate of parasite establishment in the host. Accurate and rapid identification of species infecting the host contributes towards achieving these goals.

Historically, control of GI nematodes was accomplished by complicated management programs which kept stocking rates low and minimized the exposure of susceptible animals to heavily infected pastures. The development of broad spectrum, highly efficacious anthelmintic drugs changed the nature of parasite control programs, and has resulted in a situation where parasite control now relies almost exclusively upon the repeated administration of drugs to a large percentage of herd members. This increase in drug usage has resulted in the selection of resistant parasites (Vermunt et al., 1995; Hosking et al., 1996; Stafford and Coles, 1999), the emergence of which has coincided with heightened consumer anxiety over chemical residues in their food and local environment. Consequently, there is a trend towards alternative livestock systems which are perceived as being more "sustainable", and as such, limit the use of anthelmintics in a herd. For livestock producers, it is important that they identify both the animals harboring high numbers of parasites, as well as those individuals carrying the more pathogenic parasite species, such as Ostertagia ostertagi in the more temperate regions. Rapid parasite identification would greatly assist the development of control programs and reduce the number of unnecessary drug treatments.

Although, sufficient morphological differences exist among adult and larval cattle GI nematodes to allow their accurate identification, the availability of similar techniques for nematode eggs remains an obstacle to reliable diagnosis. In some cases the structure and size of the egg can be diagnostic; however, in many instances, similarities among eggs from different species and even distinct genera require alternative methods for their differentiation. Presently, the method commonly utilized for GI nematodes of cattle involves in vitro cultivation of eggs to infective, third stage larvae (L3), followed by recovery and morphological identification (Keith, 1953). This procedure is labor intensive, time consuming (Berrie et al., 1988; Hubert and Kerboeuf, 1984) and prone to errors due to variation in egg viability and parasite development in culture (Berrie et al., 1988; Dobson et al., 1992; Gasbarre et al., 1996). Other methods utilizing microscopic examination require measurements on as many as 20 different parameters per egg, followed by computer analysis and assimilation of the data (Georgi and McCulloch, 1989; Sommer, 1996). Clearly, these procedures are equally labor intensive, require expensive equipment and the creation of a large enough data set to decrease the error rate. Christensen et al. (1994) identified and cloned, genus-specific repetitive DNA fragments from a number of important genera of strongylid nematodes infecting cattle and used these as probes to screen parasite genomic DNA. While this method 
is sensitive, specific and adaptable to screening egg-derived DNA, as designed, the technique employs radioisotopes and requires multiple assays to distinguish mixtures of eggs. Utilizing a unique internal repeat within the ITS 1 of O. ostertagi and Ostertagia lyrata, the most pathogenic of nematode species infecting cattle, we developed previously, a polymerase chain reaction (PCR)-based technique that collectively differentiates and quantitates these species from other common bovine GI nematodes (Zarlenga et al., 1998); however, this method is not capable of delineating among the other nematode species within a mixed population. A plethora of parasite-specific PCR primers have been generated for identifying individual nematode species some of which work at the level of a single egg (for review see Gasser, 1999). These and other similar tests require that each parasite DNA be analyzed through a matrix of primer sets and PCR reactions for identification.

The goal of the work presented herein, was to develop a simple, sensitive and rapid PCR test for simultaneously differentiating important species of GI nematodes infecting cattle which could be adapted to egg-derived DNA. The availability of such a test would curtail the number of drug treatments by targeting only those animals harboring the most pathogenic parasites and, in doing so, reduce the potential for drug residues in consumer products, decrease producer costs, and decrease the risk of resistance to drugs by reducing selective pressure on the parasites. Such a test would also provide an important and much needed tool for studies of parasite biology and epidemiology.

\section{Materials and Methods}

\subsection{Parasite isolation}

Holstein calves, acquired within $48 \mathrm{~h}$ of birth, were raised in concrete pens until 3 months of age. To ensure that all calves were nematode-free, feces were examined for parasite eggs and, as an added precaution, all animals were treated with fenbendazole (Hoechst-Roussel, Sommerville, NJ) $(5 \mathrm{mg} / \mathrm{kg}$ body weight). The calves were experimentally-infected with O. ostertagi $\left(2.5 \times 10^{5}\right.$ larvae $)$, Haemonchus placei $\left(5.0 \times 10^{4}\right.$ larvae), Oesophagostomum radiatum $\left(1.5 \times 10^{4}\right.$ larvae $)$ or Cooperia oncophora $\left(2.5 \times 10^{5}\right.$ larvae $)$. Feces were collected from infected animals for egg isolation, after which all animals were killed and adult parasites were collected from the small intestine ( $C$. oncophora), the large intestine and caecum $(O$. radiatum) or the abomasum (O. ostertagi and $H$. placei). All above listed parasites are normally maintained at the Beltsville, Maryland animal facilities. Individual parasites were morphologically confirmed (Lichtenfels, 1977; Lichtenfels et al., 1994; Lichtenfels and Hoberg, 1993) and used for genomic DNA isolation. Trichostrongylus colubriformis L3 larvae were produced by passage through jirds and were kindly provided by Dr. Timothy Geary.

\subsection{DNA isolation}

Genomic DNA was isolated from morphologically identified adult parasites by proteinase $\mathrm{K}(2 \mathrm{mg} / \mathrm{ml})$ :sodium dodecyl sulfate (SDS) $(2 \%)$ digestion at $65^{\circ} \mathrm{C}$ followed by organic extraction as described previously (Zarlenga et al., 1998). All DNA samples from adult 
parasite and L3 larvae were RNase treated and re-purified. DNA concentrations were measured spectrophotometrically at $260 \mathrm{~nm}$ and normalized for rDNA content by PCR (Zarlenga et al., 1998). DNA from T. colubriformis L3 larvae was isolated in a similar manner except that the DNA extraction buffer was supplemented to $150 \mathrm{mM}$ with $\beta$-mercaptoethanol during the proteinase K:SDS digestion step.

Parasite eggs from monospecifically-infected animals were purified by zinc sulfate flotation (Herlich, 1976). Eggs attached to cover slips, along with excess zinc salts were removed by washing with three changes of $0.1 \%$ SDS, followed by centrifugation and resuspension in $500 \mathrm{ml}$ of DNA extraction buffer (100 mM NaCl, $50 \mathrm{mM}$ EDTA, $50 \mathrm{mM}$ Tris, pH 8.0). Egg solutions were heat treated, sonicated and supplemented to $1 \%$ SDS prior to the addition of proteinase $\mathrm{K}(2 \mathrm{mg} / \mathrm{ml}$ final) and the extraction of DNA (Zarlenga et al., 1998). Where multiplex PCR was performed on total nucleic acids from egg mixtures, pre-determined amounts of each species of egg were combined prior to nucleic acid extraction. Egg-derived nucleic acid mixtures were neither RNase treated nor of sufficient quantity to measure spectrophotometrically. Thus, extracted material was dissolved to a final concentration of four egg-DNA equivalents (amount of DNA obtained from a single egg) per $\mathrm{ml} \mathrm{TE} \mathrm{(10} \mathrm{mM} \mathrm{Tris,}$ 1 mM EDTA, pH 8.0).

\subsection{Multiplex PCR}

PCR primers were synthesized which span regions within the first internal transcribed spacer (ITS 1) of O. ostertagi, the external transcribed spacers (ETS) of H. placei and C. oncophora, the second internal transcribed spacer (ITS 2) of T. colubriformis and the $3^{\prime}$-end of the ITS 1 through the $5^{\prime}$-end of the ITS 2 of $O$. radiatum, based upon existing sequence information as well as sequence data generated herein (Table 1). Internal transcribed spacer one sequences unavailable from GenBank ${ }^{\mathrm{TM}}$ were obtained by automated sequencing of PCR products generated using primers 242 ( $5^{\prime}$-ATTGGATCCAACAACCCTGAACCAG ACGTAC) and 417 (Table 1). All multiplex PCR primers were chosen manually from computer aligned, homologous sequences. Given the AT rich character of the T. colubriformis primers, an $11 \mathrm{bp}$ anchor sequence, $5^{\prime}$-CAGGGTCAGTG, was added to the $5^{\prime}$-end of each primer to enhance and stabilize binding in the presence of the other primer sets (Shuber et al., 1995). Enzymatic amplifications of adult- and egg-derived DNA were performed using primer pairs presented in Table 1 . Each primer was used at $0.20 \mu \mathrm{M}$ in a $50 \mu \mathrm{l}$ reaction, except for primers 595 and 653 which were used at $0.40 \mu \mathrm{M}$ each. All PCR reactions contained $1 \mu \mathrm{l}$ of DNA mix, $1 \%$ dimethysulfoxide, $1.25 \mathrm{U}$ of ExTaq DNA polymerase (PanVera Corporation), $200 \mu \mathrm{M}$ deoxynucleoside triphosphates, and $1 \times$ amplification buffer as supplied by the manufacturer containing $1.5 \mathrm{mM} \mathrm{MgCl}_{2}$. PCR was performed for 40 cycles on a Perkin-Elmer 9600 thermocycler as follows: $94^{\circ} \mathrm{C} 1 \mathrm{~min} ; 60^{\circ} \mathrm{C} 1 \mathrm{~min} ; 72^{\circ} \mathrm{C}$ $2 \mathrm{~min}$, succeeded by a $7 \mathrm{~min} 72^{\circ} \mathrm{C}$ soak at the end of the run. All genomic DNA mixtures used for testing the multiplex PCR assay consisted of $20 \mathrm{pg} / \mathrm{ml}$ of genomic DNA from each appropriate nematode species. Multiplex PCR amplification from egg-derived total nucleic acids contained four egg-DNA equivalents/PCR reaction. All amplification products were separated on a MetaPhor ${ }^{\mathrm{TM}}(1.8 \%)-\mathrm{SeaKem}^{\mathrm{TM}} \mathrm{GTG}^{\mathrm{TM}}(0.2 \%)$ agarose gel (BioWhittaker Molecular Applications, Rockland, ME), stained with ethidium bromide and photographed on a Biomax Gel Print 2000i photoimager. 
Table 1

Primer sets for multiplex PCR

\begin{tabular}{|c|c|c|c|c|c|c|}
\hline Primer set & Parasite & Primer no. & $\begin{array}{l}\text { Length } \\
\text { (bp) }\end{array}$ & Location & Accession no./reference ${ }^{b}$ & Primer Sequence \\
\hline I & Ostertagia ostertagi & $\begin{array}{l}417(f)^{\mathrm{c}} \\
526(\mathrm{r})\end{array}$ & 257 & $\begin{array}{l}3^{\prime} \text { ssrDNA } \\
\text { ITS } 1\end{array}$ & $\begin{array}{l}\text { Zarlenga et al. (1998) } \\
\text { AF044933 }\end{array}$ & $\begin{array}{l}5^{\prime} \text {-TAAAAGTCGTAACAAGGTATCTGTAGGT } \\
5^{\prime} \text {-GTCTCAAGCTCAACCATAACCAACCATTGG }\end{array}$ \\
\hline II & Haemonchus placei & $\begin{array}{l}628(\mathrm{f}) \\
627(\mathrm{r})\end{array}$ & 176 & $\begin{array}{l}\text { ETS } \\
\text { ETS }\end{array}$ & $\begin{array}{l}\text { AF343971 } \\
\text { AF343971 }\end{array}$ & $\begin{array}{l}\text { 5'-CATTTTCGTCTTGGGCGATAT } \\
5^{\prime} \text { TGAGACCGCACGCGTTGATTCGAA }\end{array}$ \\
\hline III & Oesophagostomum radiatum & $\begin{array}{l}595(f) \\
653(r)\end{array}$ & 329 & $\begin{array}{l}\text { ITS } 1 \\
\text { ITS } 2\end{array}$ & $\begin{array}{l}\text { AF344881 } \\
\text { AJ006149 }\end{array}$ & $\begin{array}{l}\text { 5'-GCAGAACCGTGACTATGGTC } \\
\text { 5'-GACAAGGAGATCACGACATCAGCAT }\end{array}$ \\
\hline IV & Trichostrongylus colubriformis & $\begin{array}{l}708(f) \\
707(r)\end{array}$ & 243 & $\begin{array}{l}\text { ITS } 2 \\
\text { ITS } 2\end{array}$ & $\begin{array}{l}\text { S69220 } \\
\text { S69220 }\end{array}$ & $\begin{array}{l}\text { 5'-CAGGGTCAGTGTCGAATGGTCATTGTCAAATA } \\
\text { 5'-CAGGGTCAGTGGTTGCAATACAAATGATAATT }\end{array}$ \\
\hline $\mathrm{V}$ & Cooperia oncophora & $\begin{array}{l}618(f) \\
641(r)\end{array}$ & 151 & $\begin{array}{l}\text { ETS } \\
\text { ETS }\end{array}$ & $\begin{array}{l}\text { AF343972 } \\
\text { AF343972 }\end{array}$ & 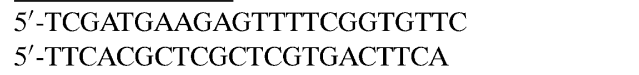 \\
\hline
\end{tabular}

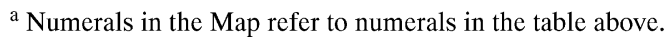

ETS

${ }^{b}$ Represents the source of the sequence from which primers were chosen.

${ }^{c}$ The (f) and (r) indicate forward $\left(5^{\prime}\right)$ and reverse $\left(3^{\prime}\right)$ primers, respectively; their location is depicted by arrows in the accompanying Map. Underlined bases in primer set IV represent anchor sequences that were not derived from the ETS. 


\section{Results}

Genomic DNA (20 pg each) from adult O. ostertagi, $H$. placei, O. radiatum, $C$. oncophora, and from $T$. colubriformis L3 larvae were amplified by multiplex PCR, both individually and in all possible combinations. The amplification products were analyzed by agarose gel electrophoresis (Fig. 1). Results indicated that, when the primers were used in a multiplex format, all appropriate parasite DNA fragments were synthesized in a predictable manner in the absence of false-positive amplification signals due to erroneous primer binding; however, the signal intensities of the specific bands were not necessarily equivalent among species. Samples containing Oesophagostomum and Trichostrongylus DNAs occasionally produced high molecular weight bands, that migrated at approximately 750 and $870 \mathrm{bp}$, respectively. These higher molecular weight fragments also were diagnostic for these species but their appearance was substantially more concentration-dependent. The same multiplex PCR format was found to amplify genomic DNA from adult Ostertagia lyrata (Weybridge, England; M.B. Lancaster), Trichostrongylus axei (Louisiana State University; J.C. Williams), Cooperia punctata (Louisiana State University; J.C. Williams) and Haemonchus contortus (Beltsville, MD) where, unlike H. placei, H. contortus generated two bands migrating at approximately 176 and 210 bp (Fig. 2). No amplification was observed when the multiplex PCR was performed on DNA purified from adult Nematodirus helvetianus (Willamette Valley, Oregon; L.G. Rickard and E.P. Hoberg) or bovine lymphocytes.

To determine the efficacy of the multiplex PCR assay on egg-derived DNA, fecal eggs purified from animals monospecifically-infected with $O$. ostertagi, $H$. placei, $O$. radiatum, or C. oncophora were combined in various ratios. For this study, Trichostrongylus eggs were unavailable; however, the reliance of the multiplex PCR test on genomic DNA makes it stage independent suggesting that anomalies arising specifically from the diagnosis of Trichostrongylus egg-derived DNA are unlikely. In the mixtures of purified eggs, the ratios of Ostertagia eggs relative to all other parasite species varied between 10 and 80\%, whereas the ratios of the other egg species were kept equivalent to one another. PCR results indicated a detection level of less than 0.5 egg-DNA equivalents for all species tested, and that relative signal intensities of each specific band were coincident with the relative level of eggs in any given sample (Fig. 3). As expected, variability in detection increased at the lower egg numbers and DNA concentrations as did non-specific amplification and smearing due to the overall high primer concentration and a reduction in specific target DNA.

\section{Discussion}

PCR has played an important role in parasite diagnosis; however, an approach for parasite differentiation using individual species and specific primers in separate reactions is time consuming given the number of different species of nematodes infecting cattle. Combining primers into a single, multiplex PCR to define a spectrum of parasites infecting the animal is more efficient thereby substantially reducing the cost and time for identification. Furthermore, to normalize signal intensities it is important to develop primers which 


\section{$\begin{array}{llllllllllllllll}1 & 2 & 3 & 4 & 5 & 6 & 7 & 8 & 9 & 10 & 11 & 12 & 13 & 14 & 15 & 16\end{array}$}

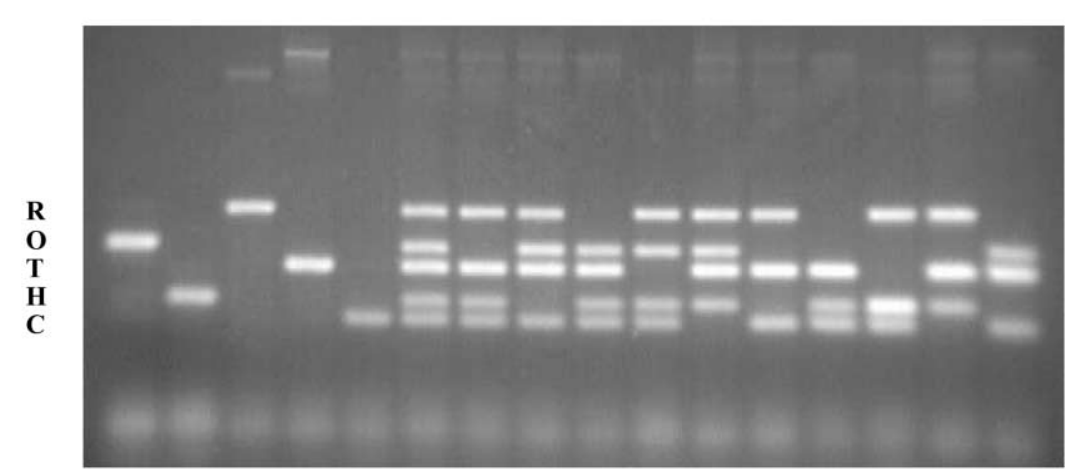
O. ostertagi
H. placei
o. radiatum
$+\quad-\quad-\quad-\quad-\quad+\quad-\quad+\quad+\quad+$
$+\quad-\quad-\quad-\quad+\quad-\quad+\quad++$
T. colubriformis
C. oncophora

$\begin{array}{llllllllllllllll}17 & 18 & 19 & 20 & 21 & 22 & 23 & 24 & 25 & 26 & 27 & 28 & 29 & 30 & 31 & 32\end{array}$

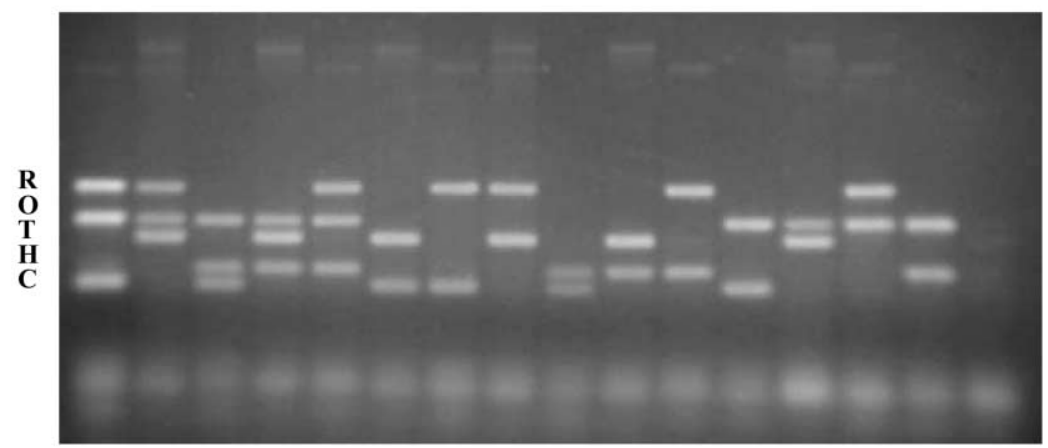

O. ostertagi

H. placei

o. radiatum

T. colubriformis

C. oncophora

Fig. 1. Multiplex PCR of parasite genomic DNA. Adult parasite-derived genomic DNAs were mixed in equal quantities (20 pg per parasite sample) in the combinations as indicated in Fig. 1 by "+". Amplification was performed for 40 cycles in a $50 \mathrm{ml}$ reaction volume using all primers of the multiplex PCR primer mix as defined in Section 2 and Table 1. PCR products $(10 \mu \mathrm{l})$ were separated by agarose gel electrophoresis and visualized by ethidium bromide staining. $\mathrm{R}=\mathrm{O}$. radiatum $(329 \mathrm{bp}) ; \mathrm{O}=$ O. ostertagi $(257 \mathrm{bp}) ; \mathrm{T}=T$. colubriformis $(243 \mathrm{bp})$; $\mathrm{H}=$ H. placei $(176 \mathrm{bp}) ; \mathrm{C}=C$. oncophora $(151 \mathrm{bp})$. Numbers adjacent to the parasite designations represent PCR fragment sizes in base pairs. 


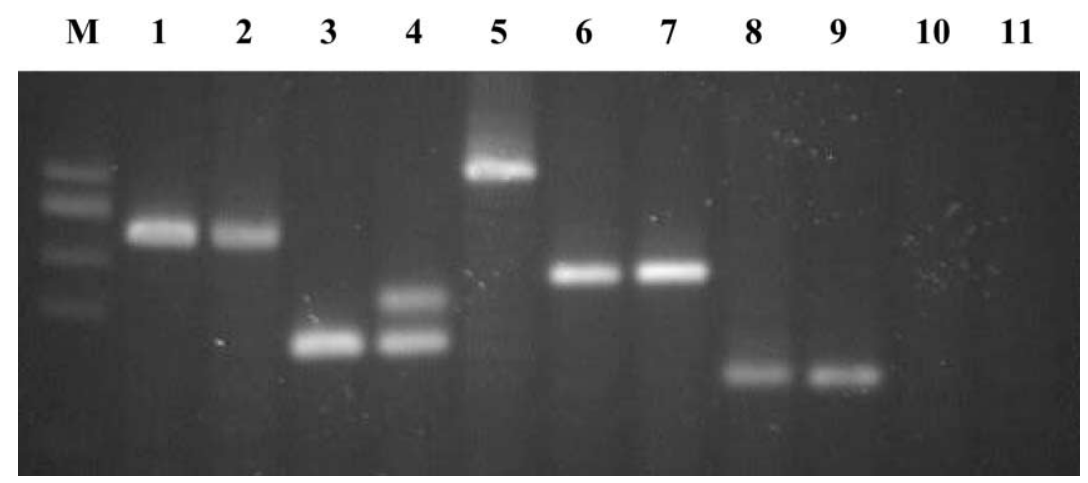

Fig. 2. Multiplex PCR using adult parasite-derived genomic DNAs from various parasite species. Enzymatic amplification using the multiplex PCR primer mix, and agarose gel electrophoresis was performed as defined in Section 2 and in the legend to Fig. 1. Lane M = Hae III FX174 markers. (1) O. ostertagi; (2) O. lyrata; (3) H. placei; (4) H. contortus; (5) O. radiatum; (6) T. colubriformis; (7) T. axei; (8) C. oncophora; (9) C. surnabada; (10) N. helvetianus; (11) Bos taurus.

amplify sequences of approximately equal representation within their respective parasite genomes. Herein, we have developed such a test for identifying species within five of the more prevalent genera of GI nematodes infecting cattle in the US, based upon sequence variation within the rDNA repeat. Using this test, we were able to successfully detect two polymorphic species of Ostertagia (O. ostertagi and O. lyrata), H. placei and H. contortus,

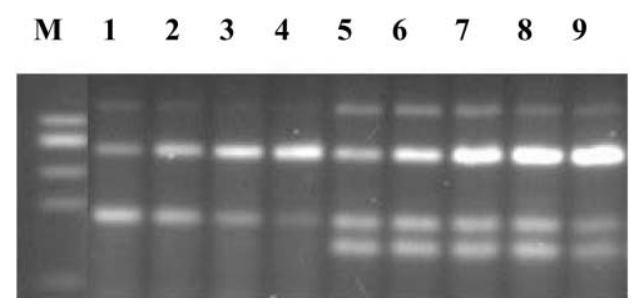

Fig. 3. Multiplex PCR of egg-derived DNA. Parasite eggs were counted and combined in the ratios define below, prior to DNA extraction. DNA $(1 \mu \mathrm{l})$ equivalent to four eggs was enzymatically amplified using the multiplex PCR primer mix. PCR products $(15 \mu \mathrm{l})$ were separated by agarose gel electrophoresis and visualized by ethidium bromide staining. Lane M = Hae III FX174 markers

$\begin{array}{clllll} & & \text { O. ostertagi } & \text { H. placei } & \text { O. radiatum } & \text { C. oncophora } \\ \text { Lane } & 10 \% & 45 \% & 45 \% & \\ 2 & 25 \% & 37 \% & 37 \% & \\ 3 & 50 \% & 25 \% & 25 \% & 30 \% \\ 4 & 75 \% & 12 \% & 12 \% & 27 \% \\ 5 & 10 \% & 30 \% & 30 \% & 20 \% \\ 6 & 20 \% & 27 \% & 27 \% & 13 \% \\ 7 & 40 \% & 20 \% & 20 \% & 7 \%\end{array}$


O. radiatum, T. colubriformis, T. axei, and $C$. oncophora/C. surnabada, as well as $C$. punctata. $H$. placei and $H$. contortus could be further delineated by the presence of a doublet within the ETS of $H$. contortus, although this would not be of diagnostic value in mixed infections containing both species. It is interesting to note that these data are consistent with those of earlier research (Zarlenga et al., 1994), suggesting that $H$. contortus may contain multiple rDNA repeat units. Given that several of the parasite species studied can infect sheep, it is possible that a modification in the multiplex PCR test described here may be applicable to the diagnosis of GI nematode infections of sheep.

Multiplex PCR addresses some problems associated with parasite diagnosis; however, there are several factors that can cause variability in both the development and utilization of such an assay. While multiplex PCR had its origins in simultaneously defining the presence or absence of multiple gene sequences within a single source, the adaptation of this technique to diagnosing mixed parasite populations must contend with signal variation resulting from unequal numbers of eggs shed by the different parasite species, and from inherent artifacts caused by the presence of more than one primer set in the reaction which may result in inaccurate diagnosis. The potential for amplification bias tends to be more pronounced as the number of primer sets increases, such as in multiplex PCR, even in the absence of fragment competition for primer binding (Braga and Gendler, 1994). This became increasingly obvious when normalized genomic DNAs from adult parasites, combined in equimolar amounts prior to PCR, periodically generated unequal quantities of PCR products as exemplified in the ethidium bromide stained gels (see Fig. 1). Bias can also occur due to dissimilar binding efficiencies between the primer sets which was the principal reason for synthesizing chimeric Trichostrongylus primers (see Shuber et al., 1995). Nonetheless, when DNA from mixtures containing increasing percentages of $O$. ostertagi eggs were amplified, signal intensities of the Ostertagia specific PCR fragment increased as well, suggesting some relationship between egg percentages and signal intensities. Some variability was observed in overall PCR signal intensities between different egg preparations and egg mixtures. We attributed this disparity to varying levels of fecal contaminants present in the egg preparations which co-purified with the DNA and adversely affected the PCR (Akane et al., 1994). Clearly, the dynamics of the reaction will not permit utilization of the multiplex PCR in a quantitative manner; nonetheless, preliminary evidence suggests that one can glean relative valuations of individual species contributions to the total egg population using this PCR assay. Given that variation in egg viability and optimum culture conditions between parasite species can skew assessment of species numbers, information on pasture seeding densities from fecal eggs may be better obtained from PCR data though this concept requires further evaluation.

To maximize the overall sensitivity of the assay, it was decided not to include as part of the multiplex primer mix, the control primer set 46 (5'-GCTGAAACTTAAAGGAATTGAC) and 50 (5'-TCAGTGTAGCGCGCGTGC) which generates a $325 \mathrm{bp}$ fragment from all parasite DNAs studied herein and substantially overlaps in size with the $O$. radiatum PCR product. Instead, the control primer set can be used separately, if necessary, to verify DNA integrity and reaction efficiencies in those rare instances where no PCR products representing any of the parasite groups covered by this test are observed in the analysis.

The primer sets developed clearly demonstrated specificity when used in a multiplex format as exemplified in Figs. 1 and 2. It is not recommended, however, that any of the multiplex primers be used separately. Preliminary evidence indicates that primer specificity 
was reduced in the absence of a multiplex format in some cases (data not shown). Zhu and Clark (1996) demonstrated that in a non-multiplex format, enhanced specificity of primer binding can be achieved in the presence of competing primers during PCR. Others have shown similar enhancement of signal specificity in the presence of tRNA (Stürzenbaum, 1999) as well as random double-stranded DNA fragments (Kainz et al., 2000). Extrapolating from this, we conclude that the presence of all primer sets alters the dynamics of primer binding thereby imparting a higher level of specificity to individual primer:template interactions. Results presented herein support such an argument (see Fig. 1 lanes 1-5).

The weak bands migrating at approximately 750 and 870 bp in Oesophagostomum and Trichostrongylus DNA, coincide with sizes predicted from uncoupled primer pairs 417/653 and $417 / 707$, respectively, where primer 417 was designed to work in conjunction with primer 526 to delineate $O$. ostertagi. The appearance of the weaker, high molecular weight bands is not unexpected given that primer 417 is a forward primer which anneals at the $3^{\prime}$-end of the ssrDNA and is substantially conserved for all parasite species investigated here, and that primers 653 and 707 are reverse primers within their respective ITS 2 regions. Nonetheless, these higher molecular weight fragments, which are also diagnostic for their respective parasite species, do not appear to impose any deleterious effects on the efficiency of the multiplex PCR.

In conclusion, we have developed a single PCR assay for distinguishing a group of common bovine GI nematodes and have presented preliminary evidence of its applicability to fecal egg-derived DNA samples. A large scale trial is underway to validate the diagnostic efficacy of this test under field conditions by comparing multiplex PCR data from egg-DNA to results obtained from classic culturing techniques, followed by morphological examination of L3 larvae. These same field trials will be used to further evaluate and optimize the detection limits of the assay.

\section{Acknowledgements}

We extend our thanks to Drs. T. Geary, E. Hoberg, M.B. Lancaster J.C. Williams, for providing us with parasite samples for use in DNA isolation and to Dr. R. Fetterer for helpful comments in preparing the manuscript.

\section{References}

Akane, A.K., Matsubara, H., Nakamura, S., Takahashi, K., Kimura, K., 1994. Identification of the heme compound co-purified with deoxyribonucleic acid (DNA) from bloodstains, a major inhibitor of polymerase chain reaction (PCR) amplification. J. Forensic Sci. 39, 362-372.

Berrie, D.A., East, I.J., Bourne, A.S., Bremner, K.C., 1988. Differential recoveries from fecal cultures of larvae of some gastro-intestinal nematodes of cattle. J. Helminthol. 62, 110-114.

Braga, V.M.M., Gendler, S.J., 1994. Co-amplification of two cDNAs in RT-PCR can alter the yield of both products. Biotechniques 17, 228-230.

Christensen, C.M., Zarlenga, D.S., Gasbarre, L.C., 1994. Ostertagi, Haemonchus, Cooperia, Oesophagostomum: construction and characterization of genus-specific DNA probes to differentiate important parasites of cattle. Exp. Parasitol. 78, 93-100. 
Dobson, R.J., Barnes, E.H., Birclijin, S.D., Gill, J.H., 1992. The survival of Ostertagia circumcincta and Trichostrongylus colubriformis in faecal culture as a source of bias in apportioning egg counts to worm species. Int. J. Parasitol. 22, 1005-1008.

Gasbarre, L.C., Leighton, E.A., Bryant, D., 1996. Reliability of a single fecal egg per gram determination as a measure of individual and herd values for Trichostrongyle nematodes of cattle. Am. J. Vet. Res. 57, 168-171.

Gasser, R.B., 1999. PCR-based technology in veterinary parasitology. Vet. Parasitol. 84, 229-258.

Georgi, J.R., McCulloch, C.E., 1989. Diagnostic morphometry: identification of helminth eggs by discriminant analysis of morphometric data. Proc. Helminthol. Soc. Wash. 56, 44-57.

Herlich, H., 1976. Attempts to produce protection against Ostertagia ostertagi in cattle. Am. J. Vet. Res. 37, 61-64.

Hosking, B.C., Watson, T.G., Leathwick, D.M., 1996. Multigeneric resistance to oxfendazole by nematodes in cattle. Vet. Rec. 138, 67-68.

Hubert, J., Kerboeuf, D., 1984. A new method for culture of larvae used in diagnosis of ruminant gastrointestinal strongylosis: comparison with fecal cultures. Can. J. Comp. Med. 48, 63-71.

Kainz, P., Schmiedlechner, A., Strack, H.B., 2000. Specificity-enhanced hot-start PCR: addition of double-stranded DNA fragments adapted to annealing temperature. Biotechniques 28, 278-282.

Keith, R.K., 1953. The differentiation of the infective larvae of some common nematode parasites of cattle. Aust. J. Zool. 1, 223-235.

Lichtenfels, J.R., 1977. Differences in the cuticular ridges among Cooperia sp. of North American ruminants with an illustrated key to species. Proc. Helminthol. Soc. Wash. 44, 111-119.

Lichtenfels, J.R., Hoberg, E.P., 1993. The systematics of nematodes that cause ostertagiasis in domestic and wild ruminants in North America an update and a key to species. Vet. Parasitol. 46, 33-53.

Lichtenfels, J.R., Pilitt, P.A., Hoberg, E.P., 1994. New morphological characters for identifying individual specimens of Haemonchus sp. (nematoda: Trichostrongyloidea) and a key to species in ruminants of North America. J. Parasitol. 80, 107-119.

Shuber, A.P., Grondin, V.J., Klinger, K.W., 1995. A simplified procedure for developing multiplex PCRs. Genome Res. 5, 488-493.

Sommer, C., 1996. Digital image analysis and identification of eggs from bovine parasitic nematodes. J. Helminthol. $70,143-151$.

Stafford, K., Coles, G.C., 1999. Nematode control practices and anthelmintic resistance in dairy calves in the south west of England. Vet. Rec. 144, 659-661.

Stürzenbaum, S.R., 1999. Transfer RNA reduces the formation of primer artifacts during quantitative PCR. Biotechniques 27, 50-52.

Vermunt, J.J., West, D.M., Pomroy, W.E., 1995. Multiple resistance to ivermectin and oxfendazole in Cooperia species of cattle in New Zealand. Vet. Rec. 137, 43-45.

Zarlenga, D.S., Stringfellow, F., Nobary, M., Lichtenfels, J.R., 1994. Cloning and characterization of ribosomal RNA genes from three species of Haemonchus (nematoda: Trichostrongyloidea) and identification of PCR primers for rapid differentiation. Exp. Parasitol. 78, 28-36.

Zarlenga, D.S., Gasbarre, L.C., Boyd, P., Leighton, E., Lichtenfels, J.R., 1998. Identification and semi-quantification of Ostertagia ostertagi eggs by enzymatic amplification of ITS 1 sequences. Vet. Parasitol. 77, 245-257.

Zhu, K.Y., Clark, J.M., 1996. Addition of a competitive primer can dramatically improve the specificity of PCR amplification of specific alleles. Biotechniques 21, 586-590. 